\title{
Comparison of efficacy and safety of preoperative Chemoradiotherapy in locally advanced upper and middle/lower rectal cancer
}

Ming-Yii Huang ${ }^{1,2}$, Hsin-Hua Lee ${ }^{1}$, Hsiang-Lin Tsai ${ }^{3,4}$, Ching-Wen Huang ${ }^{3,4}$, Yung-Sung Yeh ${ }^{3,5,6}$, Cheng-Jen Ma ${ }^{3,7}$, Chun-Ming Huang ${ }^{1}$, Chiao-Yun Chen ${ }^{8,9}$, Joh-Jong Huang ${ }^{10^{*}}$ and Jaw-Yuan Wang ${ }^{3,4,11,12,13^{*}}$ (D)

\begin{abstract}
Background: We aimed to explore the efficacy and safety profile of preoperative neoadjuvant chemoradiation (NACRT) in locally advanced rectal cancer (LARC) in upper rectum versus middle/lower rectum.

Methods: The study included 173 patients with stage II or III (T2-4b, NO-2b) LARC who underwent NACRT followed by total mesorectal excision (TME) between January 2011 and October 2016. Cox regression, log-rank test, and Kaplan-Meier curves were calculated.

Results: Among the 173 patients, 58 had lesions in the upper rectum and 115 patients had lesions in middle/lower rectum. In a median follow-up of 35 months (range, 6-73 months), the 5-year disease-free survival (DFS) and overall survival (OS) were $84 \%$ and $88 \%$ for the patients with upper rectal cancer and $77 \%$ and $68 \%$ for those with middle/lower rectal cancer ( $P=0.251$ and $P=0.058$, respectively). The 5-year DFS $(P=0.012)$ and OS $(P=0.003)$ were better in the NACRT responders [tumor regression grade (TRG) 0 or 1] compared with nonresponders (TRG 2 or 3 ). The independent prognostic factor of favorable response to NACRT was the FOLFOX regimen $(P=0.004)$.

Conclusions: Patients with LARC in the upper rectum who underwent NACRT followed by TME had similar DFS and a trend toward longer OS, compared with those who had middle/lower rectal lesions. Furthermore, FOLFOX may yield superior results than fluoropyrimidine based regimen during NACRT. NACRT might be an alternative option for patients with LARC in the upper rectum as it has a favorable pathological complete response rate and comparable clinical outcomes when compared with patients with LARC in middle/lower rectum.
\end{abstract}

Keywords: Upper rectal cancer, Middle/lower rectal cancer, Neoadjuvant chemoradiation, FOLFOX, CCRT

\section{Background}

Most patients with rectal cancer often encounter multimodality treatment including surgery, radiotherapy (RT) and chemotherapy [1]. The 5-year relative survival rate improved from $45 \%$ from 1975 to 1977 to $70 \%$ from 2006 to 2012 for patients with regional-stage rectal cancer [2]. This improvement reflects advances in treatment such

\footnotetext{
* Correspondence: jjhua511227@gmail.com; cy614112@ms14.hinet.net ${ }^{10}$ Department of Family Medicine, Kaohsiung Medical University Hospital, No. 100 Tzyou 1st Road, Kaohsiung 807, Taiwan

${ }^{3}$ Division of Colorectal Surgery, Department of Surgery, Kaohsiung Medical University Hospital, Kaohsiung Medical University, No. 100 Tzyou 1st Road, Kaohsiung 807, Taiwan

Full list of author information is available at the end of the article
}

as preoperative neoadjuvant chemoradiation (NACRT) for locally advanced rectal cancer (LARC) [2]. By utilizing the National Cancer Data Base, researchers studied a total of 66,197 patients who had been diagnosed with stage II to III rectal adenocarcinoma and treated between 2004 and 2012. The 5-year overall survival (OS) rates for patients treated with NACRT followed by surgery, surgery and adjuvant chemoradiotherapy (CRT), surgery alone, and definitive CRT were $72.4 \%, 70.9 \%, 44.9 \%$, and $48.8 \%$, respectively [3]. The trimodality therapy of NACRT followed by surgery is associated with the best outcomes. The patients who received NACRT had improved OS (hazard ratio, 0.77; $P<0.01$ ) compared with those who 
received neoadjuvant multiagent chemotherapy regimens without RT. This effect was confirmed by a propensity score matching analysis (hazard ratio, $0.72 ; P=0.01$ ) [4].

According to the data compiled by the European Society for Medical Oncology (ESMO) Guidelines Committee, preoperative RT or CRT reduces the rate of local recurrence without improving OS for middle/lower stage II/III rectal cancers $[5,6]$. Considering the heterogeneity among literature reviews, the ESMO panelists did not recommend preoperative NACRT for upper rectal ancers (>12 cm from the anal verge) above the peritoneal reflection [7-13]. There is significant unmet clinical need for this group of patients.

As for chemotherapy regimen, the combination of 5-FU and oxaliplatin (FOLFOX) was shown to improve survival and prolong time to progression in previously untreated metastatic colon and rectal cancer when compared with fluorouracil plus leucovorin or irinotecan [14]. When adding oxaliplatin to NACRT, results have not been conclusive in terms of survival, although improved pathological complete response rate $(\mathrm{pCR})$ was found in some studies [15-19].

Thus, we investigated patients with LARC in the upper versus middle/lower rectum who underwent preoperative treatment with FOLFOX- or fluoropyrimidine-based NACRT and present their pCR, NACRT-related toxicity, prognostic factors, and oncological outcomes.

\section{Materials and methods}

\section{Patients}

We analyzed a series of 173 consecutive patients with pathologically proven rectal adenocarcinoma (T2-4b, N0-2b) between January 2011 and October 2016. All the patients had no metastasis at diagnosis and received preoperative NACRT followed by total mesorectal excision (TME). The exclusion criteria for this study were local excision of tumor, a history of prior pelvic irradiation, and a history of malignancies other than rectal cancer. The present study was approved by the Institutional Review Board (IRB) of Kaohsiung Medical University Hospital (IRB approval number: KMUHIRBE(II)-20170179).

All the patients underwent pretreatment workups comprising a physical examination, a history review, a colonoscopy, a tumor biopsy, chest radiography, abdominal computed tomography $(\mathrm{CT})$, pelvic magnetic resonance imaging (MRI), a serum carcinoembryonic antigen (CEA) test, and routine laboratory studies. The median follow-up was 35 months (range, 6-73 months). As measured by rigid sigmoidoscopy or pelvic CT scan, the distal extension of all tumors was no more than $15 \mathrm{~cm}$ from the anal margin and categorized as lower (up to $5 \mathrm{~cm}$ ), middle (from $>5$ to $10 \mathrm{~cm}$ ) or upper (from $>10$ to $15 \mathrm{~cm}$ ). The tumor stage was classified according to the seventh edition of the American Joint Committee on Cancer (AJCC) Cancer Staging Manual and Handbook [20].

\section{Ethics approval statement}

The present study (KMUHIRB-E(II)-20,170,179) was conducted under compliance of the IRB regulations of Kaohsiung Medical University Hospital. All patients provided written informed consent prior to NACRT and TME. Patient information was anonymized and deidentified before analysis. All data were analyzed anonymously and retrospectively. The need for consent was waived by the IRB for retrospective chart reviews.

\section{Chemotherapy}

During NACRT, 94 patients were treated with a fluoropyrimidine-based regimen that comprised one of the following: (i) $5-\mathrm{FU}\left(350 \mathrm{mg} / \mathrm{m}^{2}\right.$, intravenous bolus) and leucovorin $\left(20 \mathrm{mg} / \mathrm{m}^{2}\right.$, intravenous bolus) on days 1 through 5 and days 21 through 25 fractions of RT, once every 2 weeks; or (ii) six cycles of capecitabine $850 \mathrm{mg} / \mathrm{m}^{2}$ twice daily for 14 days, followed by 7 days of rest after each cycle. Moreover, 79 patients were prescribed with FOLFOX biweekly, concurrent with radiotherapy. Oxaliplatin $\left(85 \mathrm{mg} / \mathrm{m}^{2}\right)$ on the first day, folinic acid $\left(400 \mathrm{mg} / \mathrm{m}^{2}\right)$, and a $46-\mathrm{h}$ infusion of 5 -FU $\left(2800 \mathrm{mg} / \mathrm{m}^{2}\right)$ were given.

\section{Radiotherapy}

All patients were asked to void and then drink 8 oz. of water half an hour before CT simulation and each fraction of RT. CT-based treatment planning was performed to identify bowel and bladder volumes, and minimize the exposure of these organs. Each patient was simulated in the supine position in a customized thermoplastic immobilization cast.

Three-dimensional conventional radiotherapy (3D-CRT) was delivered using a $2100 \mathrm{C} / \mathrm{D}$ linear accelerator (Varian Medical Systems, Palo Alto, CA). For the 3D-CRT plan, we used a three-field technique with two opposed lateral fields and one posterior-anterior field with wedges and photon energy of $10 \mathrm{MV}$. The radiation portal fields were designed as: (i) superior border: L5-S1 interspace, (ii) inferior border: $3-4 \mathrm{~cm}$ below the primary tumor, (iii) lateral border: $1.5 \mathrm{~cm}$ outside the true bony pelvis, (iv) posterior margin: $1.5 \mathrm{~cm}$ behind the anterior bony sacral margin, and (v) anterior border: posterior border of the symphysis pubis. Pelvic radiotherapy consisted of 45 Gy in 25 fractions over a period of 5 weeks; followed by a boost dose of 5.4 Gy administered in 3 fractions to the primary tumor and involved nodes by two lateral fields. The dose specification for 3D-CRT is to encompass the planning target volume (PTV) in all directions with the 95\% isodose line. The volume receiving more than $110 \%$ of the dose prescribed to the PTV was minimized. The reference point 
was selected either in the central part of PTV or at the intersection of the beam axes by International Commission on Radiation Units and Measurements (ICRU) (Report 50 and 62).

The image-guided intensity-modulated radiotherapy (IG-IMRT) plans were generated either with a Hi-Art helical tomotherapy unit, version 2.2.4.1 (TomoTherapy, Inc., Madison, WI), or Eclipse, version 8.6 (Varian Medical Systems Inc., Palo Alto, USA). TomoTherapy combines a rotational IMRT with a translational movement of the couch. A fixed-jaw mode with a field width of 2.5 or $5 \mathrm{~cm}$ was used for treatment planning. The pitch varied from 0.215 to 0.287 . The modulation factor ranged from 2 to 3 , depending on the homogeneity and conformity. The gross tumor volume encompassed rectal tumors and clustered lymph nodes or lymph nodes with a diameter greater than $1 \mathrm{~cm}$. The clinical target volume (CTV) included the primary tumor, the mesorectum, the sacral canal, and the perirectal, presacral, hypogastric, obturator, and internal iliac lymphatic drainage. A superior, an inferior, and a radial margin of 5 to $7 \mathrm{~mm}$ outside the CTV were added to form the PTV.

In the IG-IMRT group, the tumor and boost beams were combined in one integrated treatment plan; thus, these patients were treated with the same plan for each fraction throughout the entire course of RT. Fractionation schemes were 25 daily fractions of 1.8 Gy to the pelvis and 2 Gy to the rectal tumor and involved nodes. Optimization was addressed to reduce the dose for the bowel, bladder, and femoral heads. These constraints were also applied to the IMRT treatment plans on Varian and comprised beams with multileaf collimator shielding conformal to the PTV. The goal was to encompass the PTV in all directions with the 95\% isodose line. Volumes receiving more than $110 \%$ of the dose prescribed to the PTV were minimized. Volumetric arc therapy was used when suitable. The IMRT plans were reviewed using ICRU 83 recommendations. Before each fraction of RT, patients were repositioned according to image guidance through a megavoltage or cone beam CT, which was coregistered with a planning kilovoltage CT. A dose of 50 Gy was prescribed to the $\mathrm{PTV}_{50}$ (tumor and enlarged nodes) and 45 Gy to the $\mathrm{PTV}_{45}$ (pelvic nodal area) by simultaneous integrated boost scheme in the IG-IMRT group. All dose schedules were given 5 days per week.

\section{Surgery}

All 173 patients had TME with a median of 10 weeks (range, 6-22) after completion of the NACRT. TME was performed for each patient so that all the mesorectal fat and the encompassing lymph nodes were meticulously excised [17, 21]. Twenty-five patients with clinical T4 classification had extended adjacent visceral resection. We performed anal sphincter-sparing surgery when applicable, with primary anastomosis and/or temporary diverting colostomies.

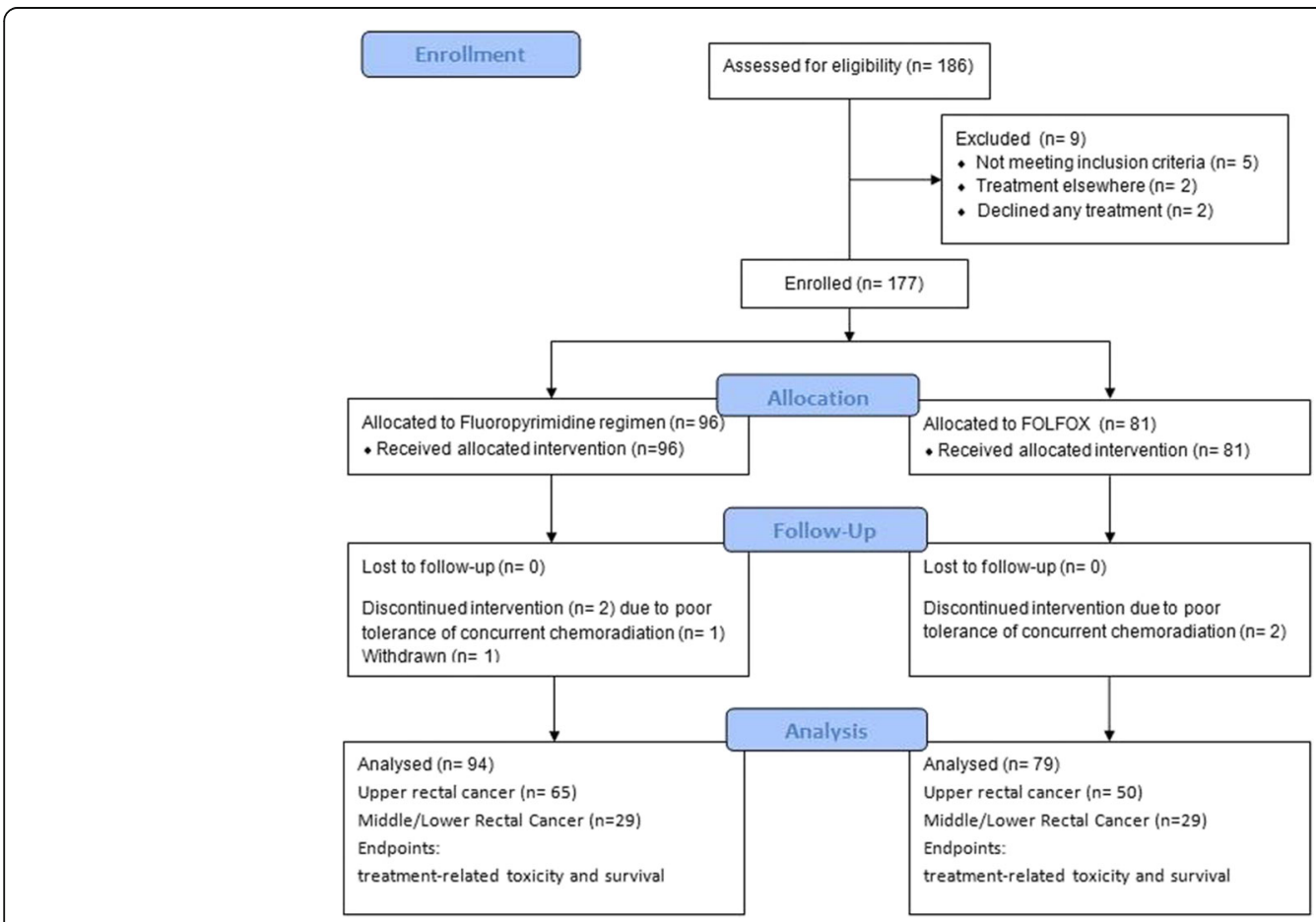

Fig. 1 Patient enrollement flow diagram 
Table 1 Patient characteristics in upper rectum and middle/lower rectum groups

\begin{tabular}{|c|c|c|c|c|c|c|c|}
\hline \multirow[t]{2}{*}{ Characteristics } & \multirow{2}{*}{$\begin{array}{l}\text { Total } \\
\mathrm{N}\end{array}$} & \multirow[b]{2}{*}{ (\%) } & \multirow{2}{*}{$\begin{array}{l}\text { Upper } \\
n=58\end{array}$} & \multirow[b]{2}{*}{$(\%)$} & \multicolumn{2}{|l|}{ Middle/Lower } & \multirow[t]{2}{*}{$P$-value } \\
\hline & & & & & $n=115$ & $(\%)$ & \\
\hline Age, median, year (range) & $61(34-93)$ & & $63.5(34-87)$ & & 61(34-93) & & 0.268 \\
\hline \multicolumn{8}{|l|}{ Age } \\
\hline$<65$ & 109 & 63 & 35 & 60.3 & 74 & 64.3 & \multirow[t]{2}{*}{0.607} \\
\hline$>=65$ & 64 & 37 & 23 & 39.7 & 41 & 35.7 & \\
\hline \multicolumn{8}{|l|}{ Gender } \\
\hline Male & 115 & 66.5 & 33 & 56.9 & 82 & 71.3 & \multirow[t]{2}{*}{0.063} \\
\hline Female & 58 & 33.5 & 25 & 43.1 & 33 & 28.7 & \\
\hline \multicolumn{8}{|l|}{ Clinical tumor depth } \\
\hline $\mathrm{T} 2$ & 11 & 6.4 & 3 & 5.2 & 8 & 7 & \multirow[t]{4}{*}{0.108} \\
\hline T3 & 137 & 79.2 & 41 & 70.7 & 96 & 83.5 & \\
\hline T4a & 13 & 7.5 & 10 & 17.2 & 3 & 2.6 & \\
\hline T4b & 12 & 6.9 & 4 & 6.9 & 8 & 7 & \\
\hline \multicolumn{8}{|c|}{ Clinical lymph node metastasis } \\
\hline NO & 28 & 16.2 & 7 & 12.1 & 21 & 18.3 & \multirow[t]{4}{*}{0.611} \\
\hline N1 & 106 & 61.3 & 40 & 69 & 66 & 57.4 & \\
\hline $\mathrm{N} 2 \mathrm{a}$ & 28 & 16.2 & 10 & 17.2 & 18 & 15.7 & \\
\hline $\mathrm{N} 2 \mathrm{~b}$ & 11 & 6.4 & 1 & 1.7 & 10 & 8.7 & \\
\hline \multicolumn{8}{|l|}{ Clinical stage } \\
\hline 2 & 28 & 16.2 & 7 & 12.1 & 21 & 18.3 & \multirow[t]{2}{*}{0.297} \\
\hline 3 & 145 & 83.8 & 51 & 87.9 & 94 & 81.3 & \\
\hline \multicolumn{8}{|l|}{ Pretreatment CEA (ng/ml) } \\
\hline$<=5$ & 110 & 63.6 & 35 & 60.3 & 75 & 65.2 & \multirow[t]{2}{*}{0.53} \\
\hline$>5$ & 63 & 36.4 & 23 & 39.7 & 40 & 34.8 & \\
\hline \multicolumn{8}{|l|}{ Concurrent chemotherapy } \\
\hline Fluoropyrimidine & 94 & 54.3 & 29 & 50 & 65 & 56.5 & \multirow[t]{2}{*}{0.416} \\
\hline FOLFOX & 79 & 45.7 & 29 & 50 & 50 & 43.5 & \\
\hline \multicolumn{8}{|l|}{ RT technique } \\
\hline $3 \mathrm{DCRT} \mathrm{T}^{\mathrm{a}}$ & 44 & 25.4 & 15 & 25.9 & 29 & 25.2 & \multirow[t]{2}{*}{0.927} \\
\hline IG-IMRT & 129 & 74.6 & 43 & 74.1 & 86 & 74.8 & \\
\hline \multicolumn{8}{|l|}{ Median RT dose, Gy (range) } \\
\hline $5000(4500-5400)$ & & & \multicolumn{2}{|l|}{$5000(4500-5040)$} & \multicolumn{2}{|l|}{$5000(4500-5400)$} & 0.454 \\
\hline Adjuvant chemotherapy & & & & & & & \\
\hline Yes & 122 & 70.5 & 44 & 75.9 & 78 & 67.8 & 0.274 \\
\hline No & 51 & 29.5 & 14 & 24.1 & 37 & 32.2 & \\
\hline Median follow-up, month & & & & & & & \\
\hline & $35(6-73)$ & & $32(7-71)$ & & $36(6-73)$ & & 0.992 \\
\hline
\end{tabular}

${ }^{a}$ three-dimensional conventional radiotherapy; ${ }^{b}$ image guided intensity modulated radiotherapy

\section{Toxicity}

The surgeons and radiation oncologists recorded acute toxicities according to the Common Terminology Criteria of Adverse Events (CTCAE), version 4.03 (http://ctep.cancer.gov/reporting/ctc.html). The scoring was performed as the patients underwent the treatment administered by the attending physicians and once per week during NACRT. As for the skin care management strategy, topical silver sulfadiazine (SSD) was prescribed for acute radiation dermatitis grade 2 or higher. Those patients who required it received SSD cream $1 \%$, once per day, preferably after a shower or bath. When 
Table 2 Patient characteristics in upper rectum and middle/lower rectum groups

\begin{tabular}{|c|c|c|c|c|c|c|c|}
\hline \multirow[t]{2}{*}{ Characteristics } & \multirow{2}{*}{$\begin{array}{l}\text { Total } \\
\mathrm{N}\end{array}$} & \multirow[b]{2}{*}{ (\%) } & \multirow{2}{*}{$\begin{array}{l}\text { Upper } \\
n=58\end{array}$} & \multirow[b]{2}{*}{$(\%)$} & \multicolumn{2}{|c|}{ Middle/Lower } & \multirow[t]{2}{*}{$P$-value } \\
\hline & & & & & $n=115$ & $(\%)$ & \\
\hline \multicolumn{8}{|l|}{ Pathologic tumor depth } \\
\hline урт0 & 39 & 22.5 & 11 & 19 & 28 & 24.3 & \multirow[t]{6}{*}{0.076} \\
\hline ypT1 & 16 & 9.2 & 4 & 6.9 & 12 & 10.4 & \\
\hline урт2 & 43 & 24.9 & 12 & 20.7 & 31 & 27 & \\
\hline урт3 & 72 & 41.6 & 29 & 50 & 43 & 37.4 & \\
\hline урТ4а & 1 & 0.6 & 0 & 0 & 1 & 0.9 & \\
\hline ypT4b & 2 & 1.2 & 2 & 3.4 & 0 & 0 & \\
\hline \multicolumn{8}{|l|}{ Pathologic lymph node metastasis } \\
\hline ypNo & 132 & 76.3 & 47 & 81 & 85 & 73.9 & \multirow[t]{6}{*}{0.105} \\
\hline ypN1a & 17 & 9.8 & 6 & 10.3 & 11 & 9.6 & \\
\hline ypN1b & 10 & 5.8 & 3 & 5.2 & 7 & 6.1 & \\
\hline ypN1c & 5 & 2.9 & 1 & 1.7 & 4 & 3.5 & \\
\hline ypN2a & 6 & 3.5 & 1 & 1.7 & 5 & 4.3 & \\
\hline ypN2b & 3 & 1.7 & 0 & 0 & 3 & 2.6 & \\
\hline \multicolumn{8}{|l|}{ Pathologic complete response } \\
\hline Yes & 39 & 22.5 & 11 & 19 & 28 & 24.3 & \multirow[t]{2}{*}{0.424} \\
\hline No & 134 & 77.5 & 47 & 81 & 87 & 75.7 & \\
\hline Median number of resected nodes & \multicolumn{2}{|l|}{$11(0-25)$} & \multicolumn{2}{|l|}{$11(5-25)$} & \multicolumn{2}{|l|}{$11(0-23)$} & \multirow[t]{2}{*}{0.91} \\
\hline Median number of involved nodes & $0(0-9)$ & & $0(0-4)$ & & $0(0-9)$ & & \\
\hline \multicolumn{8}{|l|}{ Tumor regression grade } \\
\hline 0 & 39 & 22.5 & 11 & 19 & 28 & 24.3 & \multirow[t]{4}{*}{0.371} \\
\hline 1 & 58 & 33.5 & 27 & 46.6 & 31 & 27 & \\
\hline 2 & 52 & 30.1 & 14 & 24.1 & 38 & 33 & \\
\hline 3 & 24 & 13.9 & 6 & 10.3 & 18 & 15.7 & \\
\hline \multicolumn{8}{|l|}{ Circumferential resection margin } \\
\hline Negative & 167 & 96.5 & 55 & 94.8 & 112 & 97.4 & \multirow[t]{2}{*}{0.404} \\
\hline Positive & 6 & 3.5 & 3 & 5.2 & 3 & 2.6 & \\
\hline \multicolumn{8}{|l|}{ Perineural invasion } \\
\hline Negative & 140 & 80.9 & 47 & 81 & 93 & 80.9 & \multirow[t]{2}{*}{0.979} \\
\hline Positive & 33 & 19.1 & 11 & 19 & 22 & 19.1 & \\
\hline \multicolumn{8}{|l|}{ Lymphovascular invasion } \\
\hline Negative & 152 & 87.9 & 52 & 89.7 & 100 & 87 & 0.608 \\
\hline Positive & 21 & 12.1 & 6 & 10.3 & 15 & 13.413 & \\
\hline Tumor differentiation & & & & & & & \\
\hline Well & 13 & 7.5 & 4 & 6.9 & 9 & 7.8 & 0.996 \\
\hline Moderately & 153 & 88.4 & 52 & 89.7 & 101 & 87.8 & \\
\hline Poorly & 7 & 4 & 2 & 3.4 & 5 & 4.4 & \\
\hline Pathologic T stage & & & & & & & \\
\hline Downstaging & 112 & 64.7 & 34 & 58.6 & 78 & 67.8 & 0.462 \\
\hline Stable & 55 & 31.8 & 23 & 39.7 & 32 & 27.8 & \\
\hline Progressive & 6 & 3.5 & 1 & 1.7 & 5 & 4.3 & \\
\hline
\end{tabular}


Table 2 Patient characteristics in upper rectum and middle/lower rectum groups (Continued)

\begin{tabular}{|c|c|c|c|c|c|c|c|}
\hline \multirow[t]{2}{*}{ Characteristics } & \multirow{2}{*}{$\begin{array}{l}\text { Total } \\
\mathrm{N}\end{array}$} & \multirow[b]{2}{*}{$(\%)$} & \multirow{2}{*}{$\begin{array}{l}\text { Upper } \\
n=58\end{array}$} & \multirow[b]{2}{*}{ (\%) } & \multicolumn{2}{|c|}{ Middle/Lower } & \multirow[t]{2}{*}{$P$-value } \\
\hline & & & & & $n=115$ & $(\%)$ & \\
\hline \multicolumn{8}{|c|}{ Pathologic N stage } \\
\hline Downstaging & 117 & 67.6 & 41 & 70.7 & 76 & 66.1 & 0.21 \\
\hline Stable & 48 & 27.7 & 17 & 29.3 & 31 & 26.9 & \\
\hline Progressive & 8 & 4.6 & 0 & 0 & 8 & 7 & \\
\hline \multicolumn{8}{|c|}{ Pathologic TN stage } \\
\hline Downstaging & 142 & 82.1 & 50 & 86.2 & 92 & 80 & 0.115 \\
\hline Stable & 23 & 13.3 & 8 & 13.8 & 15 & 13 & \\
\hline Progressive & 8 & 4.6 & 0 & 0 & 8 & 7 & \\
\hline
\end{tabular}

chemo agents produced severe side effects, dose reduction and/or the temporary suspension of medication were exerted.

\section{Evaluation}

We assessed efficacy by using the $\mathrm{pCR}$ rate and tumor regression grade (TRG). We defined patients with TRG 0 or 1 as NACRT responders and those with TRG 2 or 3 as nonresponders. A pCR was defined as the absence of any viable residual tumor cell in the resected primary tumor and adjacent lymph nodes (ypT0N0) after NACRT. We then compared the clinical stage with the pathological stage to determine the down-staging rate. The TRG was recorded by the AJCC system [22]. A circumferential resection margin (CRM) of less than $1 \mathrm{~mm}$ was defined as a positive CRM.

The primary end points were disease-free survival (DFS) and OS. The secondary end points were acute toxicities during NACRT and the pCR rate after the preoperative NACRT. In general, the patients were observed with a standardized follow-up every 3 months after therapy for the first year and every 6 months thereafter. The length of follow-up was defined as the time from NACRT to the date of death or last follow-up. Local failure was defined as any disease recurrence within the pelvis. Any failure outside these regions was classified as a distant metastasis. Recurrence was confirmed pathologically by surgical resection, biopsy, or cytology, and/or radiological findings, which increased in size over time. Distant metastasis was recorded mostly according to chest radiography, abdominal ultrasonography, CT scan, magnetic resonance imaging, or technetium- 99 bone scintigraphy.

\section{Statistical analysis}

The data set was stratified and outcomes were compared by $\mathrm{t}$ test or chi-squared test. Univariate analyses and a multivariate Cox proportional hazards regression were used to examine the following characteristics and their potential association with the response to NACRT: age, gender, RT technique, and the tumor's distance from the anal verge, clinical tumor depth, clinical lymph node metastasis, and different chemotherapy regimens.

OS was defined as the time from the date of primary treatment to the date of death from any cause or until the date of the last follow-up. DFS was defined as the time from the date of primary treatment to the date of diagnosis for recurrence or metastatic disease or to the date of the last follow-up. Locoregional failure-free survival (LFFS) was defined as the time from the date of primary treatment to the date of diagnosis for recurrence or to the date of the last follow-up. Distant metastasis failure-free survival (DMFS) was defined as the time from the date of primary treatment to the date of diagnosis for metastatic disease or to the date of the last follow-up.

OS, DFS, LFFS, and DMFS were assessed by KaplanMeier methods and the log-rank test was used to compare time-to-event distributions. Estimated risks of death were calculated using hazard ratios (HR) with 95\% confidence intervals (CIs). The level of statistical significance was set at $P<0.05$; all reported $P$ values were two-tailed. The analyses were performed using the SPSS software package, version 19.0 for Windows (SPSS, Chicago, IL, USA).

\section{Results}

Figure 1 is the CONSORT diagram. The median age of this retrospective cohort was 61 years (range, 34-93 years). The male-to-female ratio was 2:1. Table 1 summarizes the clinical characteristics of the 173 patients, divided by the location of their tumors into the middle/lower rectum group and upper rectum group. The methods of treatment were as follows: $54.3 \%$ of patients received fluoropyrimidine-based chemotherapy; $45.7 \%$ received FOLFOX, and $74.6 \%$ underwent IG-IMRT. The median RT dose was 50 Gy (range, 45-54 Gy). No significant differences were observed in terms of age, gender, clinical $\mathrm{T}$ classification, clinical $\mathrm{N}$ classification, clinical stage, pretreatment CEA level, chemotherapy regimen, RT technique, and median RT dose, 
Table 3 Comparision of toxicity and treatment breaks in 3DCRT and IG-IMRT groups

\begin{tabular}{|c|c|c|c|c|c|c|c|c|}
\hline \multirow[t]{2}{*}{ Acute toxicity } & & & \multicolumn{2}{|c|}{$3 \mathrm{DCRT}^{\mathrm{a}}$} & \multicolumn{2}{|l|}{ IG-IMRT ${ }^{b}$} & \multirow{2}{*}{$\begin{array}{l}\text { Intra-goup } \\
P \text {-value }\end{array}$} & \multirow{2}{*}{$\begin{array}{l}\text { Inter-group } \\
P \text {-value }\end{array}$} \\
\hline & & & $n=44$ & $(\%)$ & $n=129$ & $(\%)$ & & \\
\hline \multirow[t]{8}{*}{ Skin } & Middle/Lower rectum & Grade 0 & 17 & 58.6 & 57 & 66.3 & 0.204 & 0.103 \\
\hline & & Grade 1 & 8 & 27.6 & 24 & 27.9 & & \\
\hline & & Grade 2 & 2 & 6.9 & 3 & 3.5 & & \\
\hline & & Grade 3 & 2 & 6.9 & 2 & 2.3 & & \\
\hline & Upper rectum & Grade 0 & 9 & 60 & 33 & 76.7 & 0.216 & \\
\hline & & Grade 1 & 6 & 40 & 10 & 23.3 & & \\
\hline & & Grade 2 & 0 & 0 & 0 & 0 & & \\
\hline & & Grade 3 & 0 & 0 & 0 & 0 & & \\
\hline \multirow[t]{8}{*}{$\mathrm{Gl}^{\mathrm{c}}$} & Middle/Lower rectum & Grade 0 & 13 & 44.8 & 48 & 55.8 & 0.284 & 0.071 \\
\hline & & Grade 1 & 8 & 27.6 & 21 & 24.4 & & \\
\hline & & Grade 2 & 4 & 13.8 & 9 & 10.5 & & \\
\hline & & Grade 3 & 4 & 13.8 & 8 & 9.3 & & \\
\hline & Upper rectum & Grade 0 & 6 & 35.7 & 25 & 58.1 & 0.099 & \\
\hline & & Grade 1 & 4 & 28.6 & 12 & 27.9 & & \\
\hline & & Grade 2 & 3 & 21.4 & 4 & 9.3 & & \\
\hline & & Grade 3 & 2 & 14.3 & 2 & 4.7 & & \\
\hline \multirow[t]{8}{*}{$G U^{d}$} & Middle/Lower rectum & Grade 0 & 24 & 82.8 & 79 & 91.9 & 0.014 & 0.016 \\
\hline & & Grade 1 & 2 & 6.9 & 7 & 8.1 & & \\
\hline & & Grade 2 & 1 & 3.4 & 0 & 0 & & \\
\hline & & Grade 3 & 2 & 6.9 & 0 & 0 & & \\
\hline & Upper rectum & Grade 0 & 15 & 100 & 43 & 100 & - & \\
\hline & & Grade 1 & 0 & 0 & 0 & 0 & & \\
\hline & & Grade 2 & 0 & 0 & 0 & 0 & & \\
\hline & & Grade 3 & 0 & 0 & 0 & 0 & & \\
\hline \multirow[t]{4}{*}{ Leukocytosis } & Middle/Lower rectum & Grade $0-2$ & 29 & 100 & 86 & 100 & - & - \\
\hline & & Grade 3 & 0 & 0 & 0 & 0 & & \\
\hline & Upper rectum & Grade $0-2$ & 15 & 100 & 43 & 100 & - & \\
\hline & & Grade 3 & 0 & 0 & 0 & 0 & & \\
\hline \multirow[t]{8}{*}{ Hemoglobin } & Middle/Lower rectum & Grade 0 & 7 & 24.1 & 27 & 31.4 & 0.522 & 0.448 \\
\hline & & Grade 1 & 13 & 44.8 & 37 & 43 & & \\
\hline & & Grade 2 & 8 & 27.6 & 18 & 20.9 & & \\
\hline & & Grade 3 & 1 & 3.5 & 4 & 4.7 & & \\
\hline & Upper rectum & Grade 0 & 3 & 20 & 10 & 23.3 & 0.593 & \\
\hline & & Grade 1 & 5 & 33.3 & 20 & 46.5 & & \\
\hline & & Grade 2 & 6 & 40 & 8 & 18.6 & & \\
\hline & & Grade 3 & 1 & 6.7 & 5 & 11.6 & & \\
\hline \multirow[t]{4}{*}{$\mathrm{RT}^{\mathrm{e}} \geq 40$ days } & Middle/Lower rectum & Yes & 2 & 6.9 & 5 & 5.8 & 0.834 & 0.733 \\
\hline & & No & 27 & 93.1 & 81 & 94.2 & & \\
\hline & Upper rectum & Yes & 1 & 6.7 & 2 & 4.7 & 0.764 & \\
\hline & & No & 14 & 93.3 & 41 & 95.3 & & \\
\hline
\end{tabular}


with or without postoperative adjuvant chemotherapy and follow-up time between upper rectal group and middle/lower rectal group (all $P>0.05$; Table 1).

Table 2 summarizes the pathological characteristics of the 173 patients. The pCR was $22.5 \%$, and the negative CRM rate was $96.5 \%$. The down-staging rates of the $\mathrm{T}$ and $\mathrm{N}$ classifications were $64.7 \%$ and $67.6 \%$, respectively. Additionally, $19.1 \%$ of patients had perineural invasion, $12.1 \%$ had lymphovascular invasion, and $88.4 \%$ had moderate tumor differentiation. No significant differences in pathological tumor depth, nodal classification, $\mathrm{pCR}$, median number of resected lymph nodes, TRG, CRM, perineural invasion, lymphovascular invasion, tumor differentiation, and $\mathrm{T} / \mathrm{N}$ down-staging rates were observed between the upper and middle/lower groups (all $P>0.05$; Table 2).

As shown in Table 3, IG-IMRT was associated with less acute urological toxicity compared with 3D-CRT in middle/lower group $(P=0.014)$. No acute urological toxicity was observed in the patients with upper rectal cancer. No significant differences in leukocyte counts, hemoglobin levels, dermatological and gastrointestinal side effects, and a prolonged RT course of more than 40 days between the upper rectal and middle/lower groups (all $P>0.05$ ) were observed. No new safety concerns were identified in the current study (Table 3).

\section{Survival}

Table 4 outlines the association between the NACRT responders and nonresponders by univariate and multivariate analyses. Response was significantly worse with a fluoropyrimidine-based regimen compared with that with FOLFOX $(P=0.004$, OR $=2.604 ; 95 \% \mathrm{CI}, 1.346-5.038)$. The tumor location of upper versus middle/lower rectum did not affect the NACRT response $(P=0.087$, OR $=1.847$; 95\% CI, 0.915-3.725). Age, gender, RT technique, and clinical $\mathrm{T}$ and $\mathrm{N}$ classifications were not independent prognostic factors (all $P>0.05$; Table 4).

In Fig. 2a and b, the Kaplan-Meier curves demonstrated the DFS and OS between the NACRT responders and nonresponders. Among the 173 patients, 97 patients were responders and 76 patients were nonresponders. At a median follow-up time of 35 months (range, 6-73), significant differences were observed in the 5-year DFS rates $(P=0.012)$ and 5 -year OS rates $(P=0.003)$ between the two groups. The median DFS and OS were 34.6 months versus 35.9 months for the NACRT

Table 4 Prognostic factors analysis for neoadjuvant chemoradiation responder

\begin{tabular}{|c|c|c|c|c|c|c|c|c|c|c|}
\hline \multirow[t]{3}{*}{ Characteristics } & \multirow{2}{*}{\multicolumn{2}{|c|}{ Total }} & \multirow{2}{*}{\multicolumn{2}{|c|}{$\begin{array}{l}\text { No responder } \\
T R G 2+T R G 3^{a}\end{array}$}} & \multirow{2}{*}{\multicolumn{2}{|c|}{$\begin{array}{l}\text { Responder } \\
\text { TRG0 + TRG1 }\end{array}$}} & \multirow{3}{*}{$\begin{array}{l}\text { Univariate } \\
P \text {-value }\end{array}$} & \multirow{3}{*}{$\begin{array}{l}\text { Multivariate } \\
P \text {-value }\end{array}$} & \multirow{3}{*}{ OR } & \multirow{3}{*}{$95 \% \mathrm{Cl}$} \\
\hline & & & & & & & & & & \\
\hline & $\mathrm{N}$ & $(\%)$ & $n=76$ & $(\%)$ & $n=97$ & (\%) & & & & \\
\hline \multicolumn{11}{|l|}{ Age } \\
\hline$<65$ & 109 & 63 & 50 & 65.8 & 59 & 60.8 & 0.502 & 0.439 & 0.77 & $0.397-1.493$ \\
\hline$>=65$ & 64 & 37 & 26 & 34.2 & 38 & 39.2 & & & & \\
\hline \multicolumn{11}{|l|}{ Gender } \\
\hline Male & 115 & 66.5 & 54 & 71.1 & 61 & 62.9 & 0.259 & 0.223 & 0.653 & $0.329-1.297$ \\
\hline Female & 58 & 37.1 & 22 & 28.9 & 36 & 37.1 & & & & \\
\hline \multicolumn{11}{|l|}{$\mathrm{RT}^{\mathrm{b}}$ technique } \\
\hline $3 \mathrm{DCRT} \mathrm{C}^{\mathrm{C}}$ & 44 & 25.4 & 21 & 27.6 & 23 & 23.7 & 0.557 & 0.934 & 1.031 & $0.496-2.145$ \\
\hline$|\mathrm{G}-| \mathrm{MRT} T^{\mathrm{d}}$ & 129 & 74.6 & 55 & 72.4 & 74 & 76.3 & & & & \\
\hline \multicolumn{11}{|l|}{ Location (rectum) } \\
\hline Middle/Lower & 115 & 66.5 & 56 & 73.7 & 59 & 60.8 & 0.075 & 0.087 & 1.847 & $0.915-3.725$ \\
\hline Upper & 58 & 33.5 & 20 & 26.3 & 38 & 39.2 & & & & \\
\hline \multicolumn{11}{|l|}{ Clinical tumor depth } \\
\hline $\mathrm{T} 4$ & 25 & 14.5 & 11 & 14.5 & 14 & 14.4 & 0.994 & 0.292 & 1.676 & $0.642-4.376$ \\
\hline $\mathrm{T} 2-3$ & 148 & 85.5 & 65 & 85.5 & 83 & 85.6 & & & & \\
\hline \multicolumn{11}{|c|}{ Clinical lymph node metastasis } \\
\hline$N 1-2$ & 145 & 83.8 & 66 & 86.8 & 79 & 81.4 & 0.339 & 0.137 & 1.972 & $0.805-4.832$ \\
\hline NO & 28 & 16.2 & 10 & 13.2 & 18 & 18.6 & & & & \\
\hline \multicolumn{11}{|c|}{ Concurrent chemotherapy } \\
\hline Fluoropyrimidine & 94 & 54.3 & 50 & 65.8 & 44 & 45.4 & 0.007 & 0.004 & 2.604 & $1.346-5.038$ \\
\hline FOLFOX & 79 & 45.7 & 26 & 34.2 & 53 & 54.6 & & & & \\
\hline
\end{tabular}

${ }^{\mathrm{a}}$ Tumor regression grade; ${ }^{\mathrm{b}}$ radiotherapy; ${ }^{\mathrm{c}}$ three-dimensional conventional radiotherapy; ${ }^{\mathrm{d}}$ image guided intensity modulated radiotherapy 

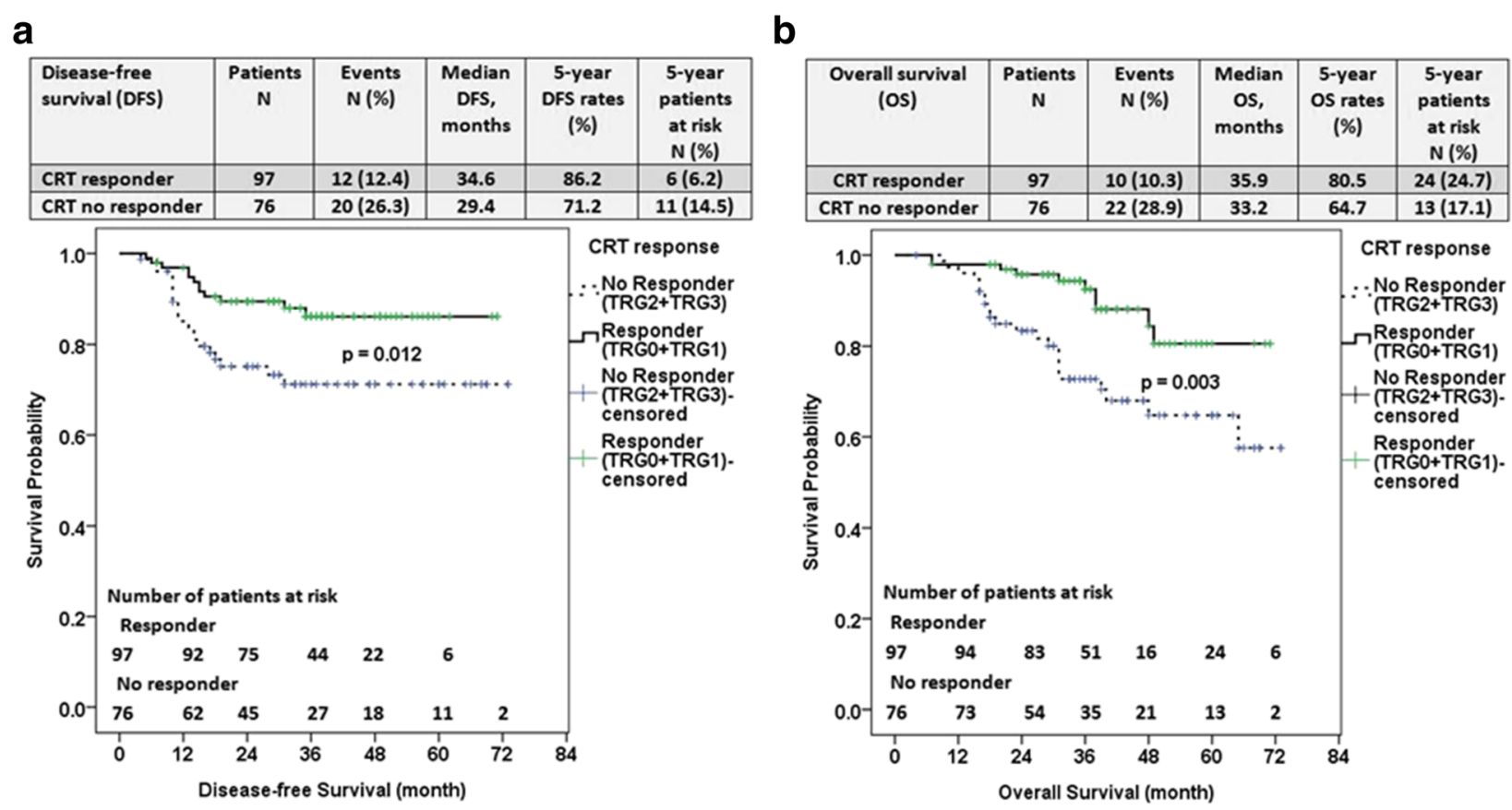

Fig. 2 Disease-free survival (DFS) and overall survival (OS) between neoadjuvant chemoradiation (NACRT) responders and nonresponders. Kaplan-Meier curves demonstrated DFS (a) and OS (b) between NACRT responders and nonresponders. Among 173 patients, 97 patients were responders and 76 patients were nonresponders. At a mean follow-up time of 35 months (range, 6-73), significant differences in the 5-year DFS $(P=0.012)$ and 5 -year OS rates $(P=0.003)$ were observed between the two groups

responders and 29.4 months versus 33.2 months for the nonresponders (Fig. 2a and b).

In Fig. $3 \mathrm{a}$ and b, 58 patients had lesions in the upper rectum and 115 patients had middle/lower rectal tumors. The 5-year DFS and 5-year OS rates were $84 \%$ and $88 \%$ for the patients with upper rectal cancer and $77 \%$ and $68 \%$ for those with middle or lower rectal cancer $(P=0.251$ and $P=0.058$, respectively). The local recurrence rates between the patients with upper versus middle/lower rectal cancer were $8.6 \%$ versus $9.6 \%$, and the distant metastasis rates were $6.9 \%$ versus $13 \%$ between upper versus middle/lower rectal cancer patients (Fig. 3a and b).

In Fig. 4a and b, the 5-year LFFS and 5-year DMFS rates were $91 \%$ and $92 \%$ for the patients with upper rectal cancer and $89 \%$ and $85 \%$ for those with middle/lower rectal cancer $(P=0.855$ and $P=0.220$, respectively).

\section{Discussion}

The present study demonstrated the long-term survival of NACRT for patients with transmural and/or nodepositive disease. Because the risk of local recurrence decreases with upper rectal tumors and the advantage of sphincter preservation is not pertinent, some studies had proposed up-front surgery $[7,8,10,11,13]$. In a multicenter randomized controlled trial from 1987 to 1993, Kaser and colleagues evaluated 725 R0-resected colorectal cancer patients without neoadjuvant or adjuvant RT or TME. The 5-year DFS and 5-year OS rates were $54 \%(95 \% \mathrm{CI}, 0.47-0.60)$ and $64 \%$ (95\%CI, $0.57-$ 0.71 ) in their patients with cancers in the lower twothirds of the rectum (11 cm or less from anal verge), whereas the 5-year DFS and 5-year OS rates were 68\% (95\%CI, $0.60-0.75)$ and $79 \%(95 \% \mathrm{CI}, 0.71-0.85)$ in those with the upper-third of the rectum and recto-sigmoid junction (> 11-20 cm from anal verge), respectively [23].

In our study of 173 patients with NACRT plus TME, the 5-year DFS rate and 5-year OS rate were $84 \%$ and $88 \%$ for the patients with upper rectal cancer and $77 \%$ and $68 \%$ for those with middle/lower rectal cancer ( $P=0.251$ and $P=0.058$, respectively). Marinello et al. investigated 147 patients with upper rectal cancers who underwent partial mesorectal excision; among them only $5.6 \%$ received NACRT. Their 5-year actuarial DFS was $82.0 \%$ in a single-institution, retrospective study [24].

Roh et al. identified 244 patients with clinical T3, T4, or node-positive rectal cancer who were randomly assigned to preoperative or postoperative chemoradiotherapy from the NSABP R-03 (National Surgical Adjuvant Breast and Bowel Project R-03) trial [25]. They found NACRT significantly increased DFS and increased a trend toward improved OS. The 5-year DFS for the NACRT patients was $64.7 \%$ versus $53.4 \%$ for the postoperative patients $(P=0.011)$; however, the 5 -year OS for 


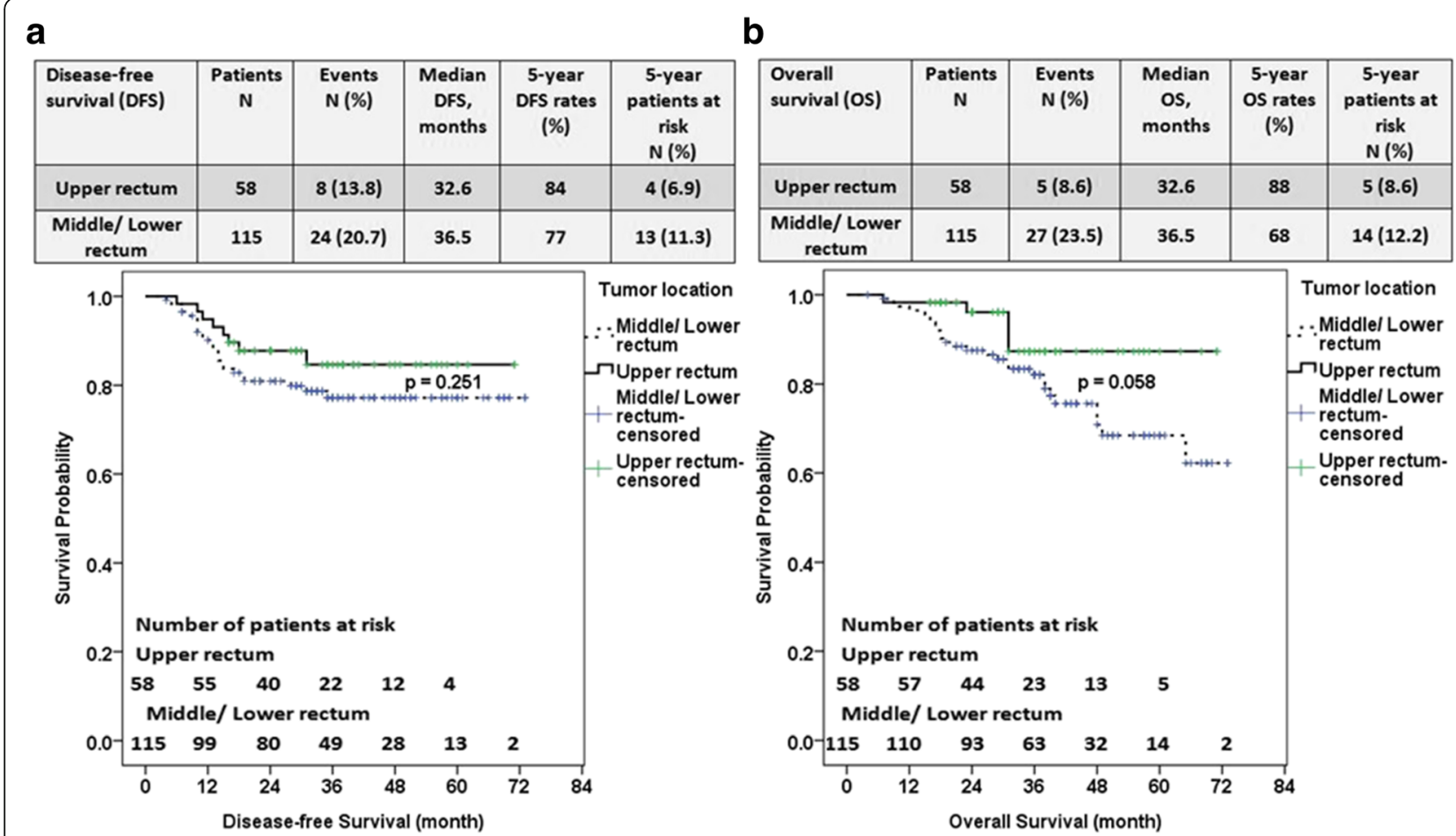

Fig. 3 Disease-free survival (DFS) (a) and overall survival (OS) (b) between upper rectal versus middle/lower rectal cancer patients receiving neoadjuvant chemoradiation therapy: 58 patients had lesions in the upper rectum and 115 patients had lesions in the middle/lower rectum. The 5-year DFS and 5 -year OS rates were $84 \%$ and $88 \%$ for the patients with upper rectal cancer and 77\% and 68\% for those with middle/lower rectal cancer $(P=0.251$ and $P=0.058$, respectively)

the NACRT patients was $74.5 \%$ versus $65.6 \%$ for the postoperative patients $(P=0.065)$ [25]. A pCR was achieved in $15 \%$ of NACRT patients, whereas in our cohort study the pCR rate was $22.5 \%$.

A multidisciplinary team of European cancer experts achieved consensus on risk-adapted treatment in that patients with cT4 tumors falling back into the pelvis might benefit from NACRT [5]. Yet, they do not recommend this treatment paradigm be applied uniformly to all patients irrespective of tumor location. Jorgren et al. conducted a population-based survey from the Swedish rectal cancer registry [9]. They assessed 4153 patients and concluded preoperative RT should be considered for upper rectal cancer. Rosenberg et al. studied 499 patients and documented that tumor distance from the anal verge was an independent prognostic parameter $(P=0.036)$, with an increased risk of cause-specific death for rectal cancers of the upper third (hazard ratio, 1.87; $P=0.007$ ) and middle third (hazard ratio, 1.43; $P=0.022)$ compared with sigmoid cancers [12]. McCarthy et al. analyzed 6 randomised controlled trials and found a reduction in local recurrence in the NACRT group in comparison to the preoperative RT group $(\mathrm{OR}=0.56,95 \% \mathrm{CI} 0.42-0.75, P<0.0001)$, yet the results for overall survival were $(\mathrm{OR}=1.0195 \% \mathrm{CI}$ $0.85-1.20, P=0.88)$ for these patients with T3-4, node positive (locally advanced) rectal cancer [26]. Abdel et al. studied 1680 patients with locally advanced rectal cancer and found NACRT increased median overall survival of 42.7 compared to 37.3 and 26.6 months for neoadjuvant chemotherapy and no neoadjuvant therapy, respectively $(P<0.0001)$ [27]. The evidence is growing that NACRT may alter prognosis for patients with rectal cancer. Neoadjuvant treatment did impact survival. Our present study corroborates this effect.

Preoperative RT improves local control in patients with rectal cancer, particularly NACRT. The question if the use of more effective chemotherapy improves OS remained unanswered [28]. As for oxaliplatin and its relation to survival, Allegra and colleagues investigated 1608 randomized patients and reported no statistically significant difference between regimens using 5-FU versus capecitabine in 3-year local-regional tumor event rates $(11.2 \%$ vs $11.8 \%)$, 5 -year DFS $(66.4 \%$ vs $67.7 \%)$, or 5 -year OS (79.9\% vs $80.8 \%)$; likewise, no statistically significant difference was found for oxaliplatin versus no oxaliplatin for the three endpoints of local-regional events, DFS, and OS ( $11.2 \%$ vs $12.1 \%, 69.2 \%$ vs $64.2 \%$, and $81.3 \%$ vs $79.0 \%$ ) [29].

In the present study, the authors compared the longterm clinical outcomes in a cohort of 173 patients who underwent NACRT followed by TME. The authors 


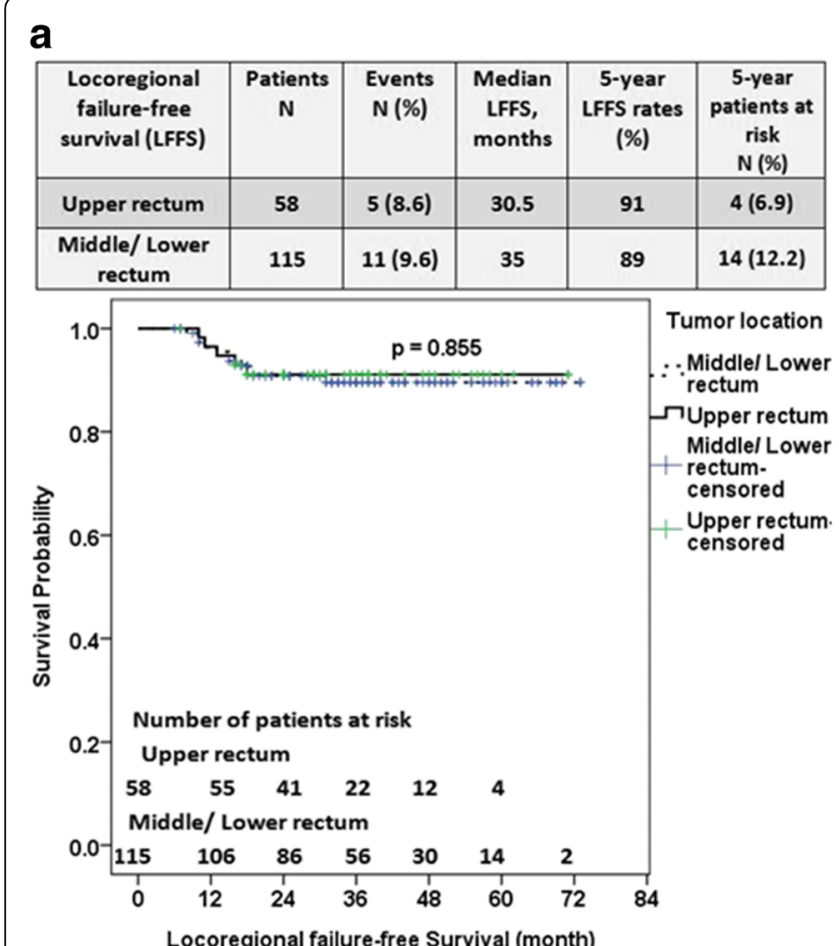

b

\begin{tabular}{|c|c|c|c|c|c|}
\hline $\begin{array}{c}\text { Distant } \\
\text { metastasis } \\
\text { failure-free } \\
\text { survival (DMFS) }\end{array}$ & $\begin{array}{c}\text { Patients } \\
\mathrm{N}\end{array}$ & $\begin{array}{c}\text { Events } \\
\mathrm{N}(\%)\end{array}$ & $\begin{array}{c}\text { Median } \\
\text { DMFS, } \\
\text { months }\end{array}$ & $\begin{array}{c}\text { 5-year } \\
\text { DMFS rates } \\
(\%)\end{array}$ & $\begin{array}{c}\text { 5-year } \\
\text { patients at } \\
\text { risk } \\
\mathrm{N}(\%)\end{array}$ \\
\hline Upper rectum & 58 & $4(6.9)$ & 30 & 92 & $5(8.6)$ \\
\hline $\begin{array}{c}\text { Middle/ Lower } \\
\text { rectum }\end{array}$ & 115 & $15(13)$ & 32.8 & 85 & $12(10.4)$ \\
\hline
\end{tabular}

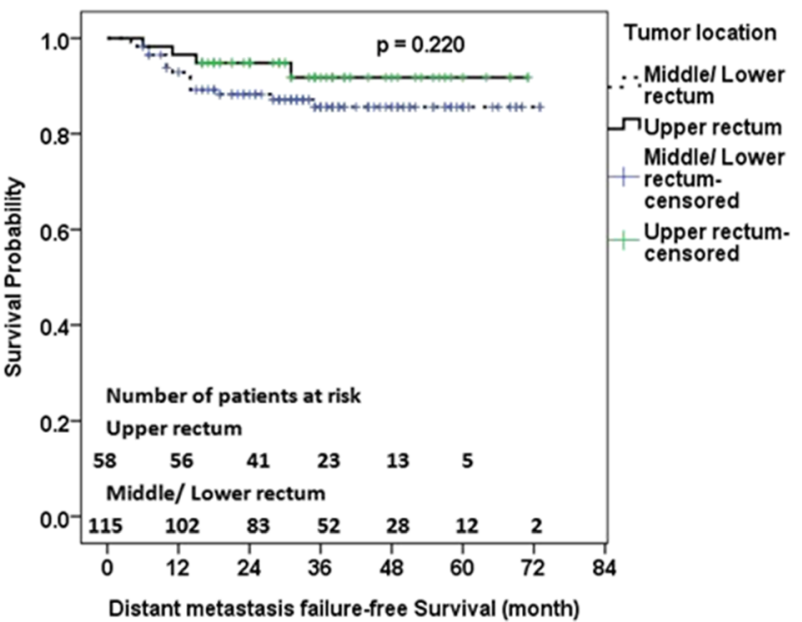

Fig. 4 Locoregional failure-free survival (LFFS) and distant metastasis failure-free survival (DMFS) between upper rectal versus middle/lower rectal cancer patients receiving neoadjuvant chemoradiation therapy. The local recurrence rate between upper versus middle/lower rectal cancer patients were $8.6 \%$ versus $9.6 \%$ (a), and the distant metastasis rate were $6.9 \%$ versus $13 \%$ between upper versus middle/lower rectal cancer patients (b). The 5-year LFFS and 5-year DMFS rates were $91 \%$ and $92 \%$ for those with upper rectal cancer and $89 \%$ and $85 \%$ for those with middle/lower rectal cancer ( $P=0.855$ and $P=0.220$, respectively)

found no significant difference in DFS or OS between patients with upper or middle/lower rectal lesions. In this study, the NACRT responders (TRG 0-1) had a higher DFS and OS than the nonresponders (TRG 2-3) (86.2\% vs $71.2 \%$ and $80.5 \%$ vs $64.7 \%$, respectively (Fig. 2a and b). Additionally, FOLFOX significantly enhanced response rate when compared with a fluoropyrimidine-based regimen. Dolinsky et al. found that patients receiving $5 \mathrm{FU} /$ oxaliplatin/RT had a high pCR rate compared with that with 5-FU/RT [15]. Huang et al. reported a pCR rate of $31.6 \%$ with the sphincter preservation rate of $92.2 \%(39 / 42)$ in patients with tumors located less than $5 \mathrm{~cm}$ from the anal verge [17]. Their 2-year overall and disease-free survivals were $94 \%$ and $87.4 \%$, respectively after NACRT with FOLFOX regimen [17]. However, adding oxaliplatin did not improve surgical outcomes but added significant toxicity according to the preliminary result from National Surgical Adjuvant Breast and Bowel Project trial R-04 [18]. They have not performed definitive analysis of local tumor control, DFS, and OS yet [18]. On the other hand, the German $\mathrm{CAO} / \mathrm{ARO} / \mathrm{AIO}-04$ study, a multicentre, open-label, randomised, phase 3 trial, concluded that adding oxaliplatin to fluorouracil-based NACRT and adjuvant chemotherapy significantly improved DFS of patients with clinically staged cT3-4 or cN1-2 rectal cancer compared with fluorouracil-based regimen (based on CAO/ARO/AIO-94) [19]. We need to see FOLFOX improve survival in more studies to make it a truly compelling new standard of care.

The limitations of the current study include the inherent biases in retrospective studies. Additionally, surgical complications were not assessed. Although the patients were not randomized by the two chemotherapy regimens or RT technique, fundamentally, similar characteristics exist between the upper and middle/lower rectum groups. In our previous study, no prominent difference in distant metastasis rate and overall survival between preoperative IG-IMRT and 3DCRT was observed [30]. In the current study, we did not focus on the merits of different RT techniques but on survival and the acute toxicity of NACRT, pCR, and TRG.

\section{Conclusion}

This present study reported an institutional experience and found survival advantages for FOLFOX in NACRT. This treatment was generally safe and well tolerated. 
The patients with upper rectal cancer who underwent NACRT followed by TME had similar DFS, LFFS, and DMFS and a trend toward a longer OS, compared with those who had middle/lower lesions. Nevertheless, a prospective study with a longer follow-up time is required and continuous data collection and analyses will be pursued steadily.

\section{Abbreviations}

3D-CRT: Three-dimensional conventional radiotherapy; 5-FU: 5-fluorouracil; AJCC: American Joint Committee on Cancer; CEA: Carcinoembryonic antigen; CRC: Colorectal cancer; CRM: Circumferential resection margin; CRT: Chemoradiotherapy; CT: Computed tomography; CTCAE: Common Terminology Criteria for Adverse Events; CTV: Clinical target volume; DFS: Disease-free survival; DMFS: Distant metastasis failure-free survival; ESMO: European Society for Medical Oncology; FOLFOX: 5-fluorouracil, leucovorin, and oxaliplatin; IG-IMRT: Image-guided intensity-modulated radiotherapy; LARC: Locally advanced rectal cancer; LFFS: Locoregional failure-free survival; MRI: Magnetic resonance imaging; NACRT: Neoadjuvant chemoradiation; OS: Overall survival; pCR: Pathologic complete response; PTV: Planning target volume; RT: Radiation therapy; SSD: Silver sulfadiazine; TME: Total mesorectal excision; TRG: Tumor regression grade

\section{Acknowledgements}

We wish to acknowledge all who generously contributed their time and expertise to this study.

\section{Funding}

This work was supported by grants from the Excellence for Cancer Research Center Grant through funding by the Ministry of Science and Technology (MOST105-2325-B-037-001, MOST106-2314-B-037-019-), as well as grants from Kaohsiung Medical University Hospital (KMUH104-4 M51 KMUH105-5R26, KMUH106-6R32, KMUH106-6R72, KMUH106-6 M28, KMUH106-6 M29, KMUH106-6 M30, KMUH106-6 M31, KMUHS10601, KMUHS10608, KMUHA10664). In addition, this study was supported by the Kaohsiung Medical University "Aim for the Top University Grant," under grant nos. KMU-TP105C01, KMU-TP105C02, KMU-TP105C11, KMU-S105011; and the Grant of Biosignature in Colorectal Cancers, Academia Sinica, Taiwan, R.O.C. (grant no. T107-001).

\section{Availability of data and materials}

All data and materials have been presented in the manuscript.

\section{Authors' contributions}

$\mathrm{JJH}$ and JYW designed the study. MYH performed the statistical analysis, participated in the interpretation of data, wrote and revised the manuscript. HHL drafted the manuscript. JJH, JYW, CJM, YSY, HLT and CWH recruited patients to the study, and treated them. CYC is a radiologist that interpreted imaging data and reviewed clinical cancer staging. MYH, HHL and $\mathrm{CMH}$ are radiation oncologists who contributed to provide radiation therapy. All authors read and approved the final manuscript.

\section{Ethics approval and consent to participate}

This present study was approved by the Institutional Review Board in Kaohsiung Medical University Hospital [KMUHIRB-E(II)-20,170,179].

\section{Consent for publication}

Not applicable.

\section{Competing Interests}

The authors declare that they have no competing interests.

\section{Publisher's Note}

Springer Nature remains neutral with regard to jurisdictional claims in published maps and institutional affiliations.

\section{Author details}

'Department of Radiation Oncology, Kaohsiung Medical University Hospital, Kaohsiung, Taiwan. ${ }^{2}$ Department of Radiation Oncology, Faculty of Medicine,
College of Medicine, Kaohsiung Medical University, Kaohsiung, Taiwan. ${ }^{3}$ Division of Colorectal Surgery, Department of Surgery, Kaohsiung Medical University Hospital, Kaohsiung Medical University, No. 100 Tzyou 1st Road, Kaohsiung 807, Taiwan. ${ }^{4}$ Department of Surgery, Faculty of Medicine, College of Medicine, Kaohsiung Medical University, Kaohsiung, Taiwan. ${ }^{5}$ Division of Trauma, Department of Surgery, Kaohsiung Medical University Hospital, Kaohsiung, Taiwan. ' ${ }^{6}$ epartment of Emergency Medicine, Kaohsiung Medical University Hospital, Kaohsiung Medical University, Kaohsiung, Taiwan. ${ }^{7}$ Division of Digestive and General Surgery, Department of Surgery, Kaohsiung Medical University Hospital, Kaohsiung, Taiwan. ${ }^{8}$ Department of Medical Imaging, Kaohsiung Medical University Hospital, Kaohsiung, Taiwan. ${ }^{9}$ Department of Radiology, Faculty of Medicine, College of Medicine, Kaohsiung Medical University, Kaohsiung, Taiwan. ${ }^{10}$ Department of Family Medicine, Kaohsiung Medical University Hospital, No. 100 Tzyou 1st Road, Kaohsiung 807, Taiwan. ${ }^{11}$ Graduate Institute of Clinical Medicine, College of Medicine, Kaohsiung Medical University, Kaohsiung, Taiwan. ${ }^{12}$ Center for Biomarkers and Biotech Drugs, Kaohsiung Medical University, Kaohsiung, Taiwan. ${ }^{13}$ College of Pharmacy, Taipei Medical University, Taipei, Taiwan.

Received: 16 November 2017 Accepted: 28 February 2018

Published online: 27 March 2018

\section{References}

1. Network. NCC. Rectal Cancer (Version 3.2017). 2017. https://www.nccn.org/ professionals/physician_gls/pdf/rectal.pdf. Accessed 13 Mar 2017.

2. Siegel RL, Miller KD, Fedewa SA, Ahnen DJ, Meester RGS, Barzi A, et al. Colorectal cancer statistics, 2017. CA Cancer J Clin. 2017;67(3):177-93. https://doi.org/10.3322/caac.21395.

3. Sineshaw HM, Jemal A, Thomas CR Jr, Mitin T. Changes in treatment patterns for patients with locally advanced rectal cancer in the United States over the past decade: an analysis from the National Cancer Data Base. Cancer. 2016;122(13):1996-2003. https://doi.org/10.1002/cncr.29993.

4. Cassidy RJ, Liu Y, Patel K, Zhong J, Steuer CE, Kooby DA, et al. Can we eliminate neoadjuvant chemoradiotherapy in favor of neoadjuvant multiagent chemotherapy for select stage I//III rectal adenocarcinomas: analysis of the National Cancer Data base. Cancer. 2017;123(5):783-93. https://doi.org/10.1002/cncr.30410.

5. Glynne-Jones R, Wyrwicz L, Tiret E, Brown G, Rödel C, Cervantes A, et al. Rectal cancer: ESMO clinical practice guidelines for diagnosis, treatment and follow-upt. Ann Oncol. 2017;28(suppl_4):iv22-40. https://doi.org/10.1093/ annonc/mdx224.

6. Sauer R, Becker H, Hohenberger W, Rödel C, Wittekind C, Fietkau R, et al. Preoperative versus postoperative Chemoradiotherapy for rectal cancer. $N$ Engl J Med. 2004;351(17):1731-40. https://doi.org/10.1056/NEJMoa040694.

7. Chan E, Wise PE, Chakravarthy AB. Controversies in radiation for upper rectal cancers. J Natl Compr Canc Netw. 2012:10(12):1567-72.

8. Fan WH, Wang FL, Lu ZH, Pan ZZ, Li LR, Gao YH, et al. Surgery with versus without preoperative concurrent chemoradiotherapy for mid/low rectal cancer: an interim analysis of a prospective, randomized trial. Chinese J of cancer. 2015;34(9):394-403. https://doi.org/10.1186/s40880-015-0024-8.

9. Jorgren F, Johansson R, Damber L, Lindmark G. Risk factors of rectal cancer local recurrence: population-based survey and validation of the Swedish rectal cancer registry. Colorectal dis. 2010;12(10):977-86. https://doi.org/10. 1111/j.1463-1318.2009.01930.x.

10. Park JS, Sakai Y, Simon NS, Law WL, Kim HR, Oh JH, et al. Long-term survival and local relapse following surgery without radiotherapy for locally advanced upper rectal cancer: an international multi-institutional study. Medicine. 2016;95(22):e2990. https://doi.org/10.1097/md.0000000000002990.

11. Popek S, Tsikitis VL, Hazard L, Cohen AM. Preoperative radiation therapy for upper rectal cancer T3,T4/Nx: selectivity essential. Clin Colorectal Cancer. 2012;11(2):88-92. https://doi.org/10.1016/j.clcc.2011.06.009.

12. Rosenberg R, Maak M, Schuster T, Becker K, Friess H, Gertler R. Does a rectal cancer of the upper third behave more like a colon or a rectal cancer? Dis Colon rectum. 2010;53(5):761-70. https://doi.org/10.1007/DCR. Ob013e3181cdb25a.

13. Wang QX, Li SH, Zhang X, Xie L, Cai PQ, An X, et al. Identification of locally advanced rectal cancer with low risk of local recurrence. PLoS One. 2015;10(1):e0117141. https://doi.org/10.1371/journal.pone.0117141.

14. Goldberg RM, Sargent DJ, Morton RF, Fuchs CS, Ramanathan RK, Williamson SK, et al. A randomized controlled trial of fluorouracil plus leucovorin, irinotecan, and oxaliplatin combinations in 
patients with previously untreated metastatic colorectal cancer. J clin oncol. 2004;22(1):23-30. https://doi.org/10.1200/jco.2004.09.046.

15. Dolinsky CM, Mahmoud NN, Mick R, Sun W, Whittington RW, Solin LJ, et al. Effect of time interval between surgery and preoperative chemoradiotherapy with 5-fluorouracil or 5-fluorouracil and oxaliplatin on outcomes in rectal cancer. J Surg Oncol. 2007;96(3):207-12. https:// doi.org/10.1002/jso.20815.

16. Garcia-Aguilar J, Chow OS, Smith DD, Marcet JE, Cataldo PA, Varma MG, et al. Effect of adding mFOLFOX6 after neoadjuvant chemoradiation in locally advanced rectal cancer: a multicentre, phase 2 trial. Lancet Oncol. 2015;16(8):957-66. https://doi.org/10.1016/ s1470-2045(15)00004-2.

17. Huang CM, Huang MY, Tsai HL, Huang CW, Ma CJ, Yeh YS, et al. An observational study of extending FOLFOX chemotherapy, lengthening the interval between radiotherapy and surgery, and enhancing pathological complete response rates in rectal cancer patients following preoperative chemoradiotherapy. Ther Adv Gastroenterol. 2016;9(5):702-12. https://doi.org/10.1177/ $1756283 \times 16656690$

18. O'Connell MJ, Colangelo LH, Beart RW, Petrelli NJ, Allegra CJ, Sharif S, et al. Capecitabine and oxaliplatin in the preoperative multimodality treatment of rectal cancer: surgical end points from National Surgical Adjuvant Breast and bowel project trial R-04. J clin oncol. 2014;32(18):1927-34. https://doi. org/10.1200/jco.2013.53.7753.

19. Rodel C, Graeven U, Fietkau R, Hohenberger W, Hothorn T, Arnold D, et al. Oxaliplatin added to fluorouracil-based preoperative chemoradiotherapy and postoperative chemotherapy of locally advanced rectal cancer (the German CAO/ARO/AIO-04 study): final results of the multicentre, open-label, randomised, phase 3 trial. Lancet Oncol. 2015;16(8):979-89. https://doi.org/ 10.1016/s1470-2045(15)00159-x

20. Greene FL. AJCC cancer staging manual. 7th ed. New York: Springer-Verlag; 2010.

21. Huang CW, Yeh YS, Su WC, Tsai HL, Choy TK, Huang MY, et al. Robotic surgery with high dissection and low ligation technique for consecutive patients with rectal cancer following preoperative concurrent chemoradiotherapy. Int J Color Dis. 2016;31(6):1169-77. https://doi.org/10.1007/s00384-016-2581-y.

22. Mace AG, Pai RK, Stocchi L, Kalady MF. American joint committee on cance and College of American Pathologists regression grade: a new prognostic factor in rectal cancer. Dis Colon rectum. 2015;58(1):32-44. https://doi.org/ 10.1097/dcr.0000000000000266.

23. Kaser SA, Froelicher J, Li Q, Muller S, Metzger U, Castiglione M, et al. Adenocarcinomas of the upper third of the rectum and the rectosigmoid junction seem to have similar prognosis as colon cancers even without radiotherapy, SAKK 40/87. Langenbeck's Arch Surg. 2015;400(6):675-82. https://doi.org/10.1007/s00423-014-1243-1.

24. Marinello FG, Frasson M, Baguena G, Flor-Lorente B, Cervantes A, Rosello $S$, et al. Selective approach for upper rectal cancer treatment: total mesorectal excision and preoperative chemoradiation are seldom necessary. Dis Colon rectum. 2015;58(6):556-65. https://doi.org/10.1097/ dcr.0000000000000349.

25. Roh MS, Colangelo LH, O'Connell MJ, Yothers G, Deutsch M, Allegra CJ, et al. Preoperative multimodality therapy improves disease-free survival in patients with carcinoma of the rectum: NSABP R-03. J Clin Oncol. 2009; 27(31):5124-30. https://doi.org/10.1200/jco.2009.22.0467.

26. McCarthy K, Pearson K, Fulton R, Hewitt J. Pre-operative chemoradiation for non-metastatic locally advanced rectal cancer. The Cochrane database of systematic rev. 2012;12:Cd008368. https://doi.org/10.1002/14651858. CD008368.pub2.

27. Abdel-Misih SR, Wei L, Benson AB 3rd, Cohen S, Lai L, Skibber J, et al. Neoadjuvant therapy for rectal cancer affects lymph node yield and status without clear implications on outcome: the case for eliminating a metric and using preoperative staging to guide therapy. J Natl Compr Canc Netw. 2016;14(12):1528-34

28. Rahbari NN, Elbers H, Askoxylakis V, Motschall E, Bork U, Buchler MW, et al. Neoadjuvant radiotherapy for rectal cancer: meta-analysis of randomized controlled trials. Ann Surg Oncol. 2013;20(13):4169-82. https://doi.org/10. 1245/s10434-013-3198-9.

29. Allegra CJ, Yothers G, O'Connell MJ, Beart RW, Wozniak TF, Pitot HC, et al. Neoadjuvant 5-FU or Capecitabine plus radiation with or without Oxaliplatin in rectal cancer patients: a phase III randomized clinical trial. J Natl Cancer Inst. 2015;107(11) https://doi.org/10.1093/jnci/djv248.

30. Huang CM, Huang MY, Tsai HL, Huang CW, Ma CJ, Lin CH, et al. A retrospective comparison of outcome and toxicity of preoperative image-guided intensity-modulated radiotherapy versus conventional pelvic radiotherapy for locally advanced rectal carcinoma. J Radiat Res. 2017;58(2):247-59. https://doi.org/10.1093/jrr/rrw098.

\section{Submit your next manuscript to BioMed Central and we will help you at every step:}

- We accept pre-submission inquiries

- Our selector tool helps you to find the most relevant journal

- We provide round the clock customer support

- Convenient online submission

- Thorough peer review

- Inclusion in PubMed and all major indexing services

- Maximum visibility for your research

Submit your manuscript at www.biomedcentral.com/submit
Biomed Central 